Proc. Indian Acad. Sci. (Earth Planet. Sci.), Vol. 94, No. 2, July 1985, pp. 159-184.

(C) Printed in India.

\title{
Short range prediction with a multi-level primitive equation model
}

\author{
S S SINGH \\ Indian Institute of Tropical Meteorology, Pune 411005 , India \\ MS received 13 January 1984; revised 6 November 1984
}

\begin{abstract}
A five-level primitive equation model in a $(x, y, p, t)$ coordinate system has been developed. A fairly sophisticated scheme of physical processes has been incorporated in the model. The model physics include air-sea interaction, cumulus parametrization, large scale condensation, dry convective adjustment, horizontal and vertical diffusion and simulated radiation. The initial balance between mass and motion fields has been obtained through a dynamic initialization scheme. The model has been integrated upto $48 \mathrm{hr}$ using input data of a case of monsoon depression. The results of initialization and forecast have been presented and discussed. Wind, temperature and vertical velocity fields have been found to retain the observed map features; after the initialization, however, the surface pressure has been considerably modified. The model produced a reasonably good forecast up to $24 \mathrm{hr}$ as far as the flow fields, rainfall region, structure of the depression and the movement of cyclonic circulation were concerned and beyond that damped rapidly. The rainfall rates were underestimated. Some of the shortcomings of the model are also discussed.
\end{abstract}

Keywords. Primitive equation model; numerical prediction; monsoon depression.

\section{Introduction}

A high resolution global model incorporating necessary physical processes is ideally suited for prediction over the monsoon belt. However, for the reason of economy and for the understanding and prediction of regional scale atmospheric systems, a regional model is highly desirable. A few tropical regional models have been developed for the research and experimental forecast and applied to case studies of the Indian summer monsoon (Krishnamurti et al 1976; Singh and Saha 1976; Das and Bedi 1978; Bedi et al 1976; Singh 1983). This study presents an application of a limited area five-level primitive equation model for prediction over the monsoon region.

\section{Model equations}

The model equation in a $(x, y, p, t)$ coordinate system on Mercator projection in flux form may be written as

$$
\begin{aligned}
\frac{\partial u}{\partial t}+m^{2}\left[\frac{\partial}{\partial x}\left(u \frac{u}{m}\right)+\frac{\partial}{\partial y}\left(u \frac{v}{m}\right)\right]+\frac{\partial}{\partial p}(\omega u)-f^{*} v & +m g \frac{\partial z}{\partial x} \\
& =-g\left(\frac{\partial \tau}{\partial p}\right)_{x}+F_{u}
\end{aligned}
$$




$$
\begin{aligned}
& \frac{\partial v}{\partial t}+m^{2}\left[\frac{\partial}{\partial x}\left(v \frac{u}{m}\right)+\frac{\partial}{\partial y}\left(v \frac{v}{m}\right)\right]+\frac{\partial}{\partial p}(\omega v)+f^{*} u+m g \frac{\partial z}{\partial y} \\
& =-g\left(\frac{\partial \tau}{\partial p}\right)_{y}+F_{v} \\
& \partial z / \partial p=-R T_{v} / p g, \\
& m^{2}\left[\frac{\partial}{\partial x}\left(\frac{u}{m}\right)+\frac{\partial}{\partial y}\left(\frac{v}{m}\right)\right]+\frac{\partial \omega}{\partial p}=0, \\
& \frac{\partial p_{s}}{\partial t}+m u_{s} \frac{\partial p_{s}}{\partial x}+m v_{s} \frac{\partial p_{s}}{\partial y}-\omega_{s}=0, \\
& \frac{\partial}{\partial t}\left(C_{p} T\right)+m^{2}\left[\frac{\partial}{\partial x}\left(C_{p} T \frac{u}{m}\right)+\frac{\partial}{\partial y}\left(C_{p} T \frac{v}{m}\right)\right]+g \frac{\partial z}{\partial p} \omega \\
& =\frac{\mathrm{d} Q}{\mathrm{~d} t}-g \frac{\partial H}{\partial p}+C_{\mathrm{p}} F_{T}, \\
& \frac{\partial q}{\partial t}+m^{2}\left[\frac{\partial}{\partial x}\left(q \frac{u}{m}\right)+\frac{\partial}{\partial y}\left(q \frac{v}{m}\right)\right]+\frac{\partial}{\partial p}(q \omega)=M-g \frac{\partial W}{\partial p}+F_{q}, \\
& T_{v}=T(1+0.62 q)
\end{aligned}
$$

Equations (1) and (2) are the equations of motion in the east and north directions respectively. Equation (3) represents the hydrostatic law and (4) is the continuity equation. Equations (5) and (6) represent the surface pressure tendency and thermodynamic energy equation respectively. Equation (7) represents the moisture continuity equation and (8) is the virtual temperature correction equation.

\section{Model structure and data}

The domain of integration extends from $6^{\circ} \mathrm{N}$ to $36^{\circ} \mathrm{N}$ and $56^{\circ} \mathrm{E}$ to $106^{\circ} \mathrm{E}$. The area is resolved by the uniform grid interval of $220 \mathrm{~km}$ on the Mercator projection. In the horizontal all the variables are defined at the same grid point (non-staggered grid). In the vertical, the model has four layers between $100 \mathrm{mb}$ and $900 \mathrm{mb}$, with a spacing of $200 \mathrm{mb}$ and a fifth layer of approximately $100 \mathrm{mb}$ thickness between $900 \mathrm{mb}$ and the ground surface (figure 1). The horizontal wind components and the geopotential height are specified at levels $200,400,600,800$ and $950 \mathrm{mb}$ and the temperature, the specific humidity and the vertical velocity are set at $300,500,700$ and $900 \mathrm{mb}$. Vertical velocity is assumed zero at $100 \mathrm{mb}$ and computed at the lower boundary through continuity equation. The temperature field between $950 \mathrm{mb}$ and the ground surface is extrapolated at each time-step from those of 700 and $900 \mathrm{mb}$. In the boundary layer between $950 \mathrm{mb}$ and ground surface, no wind shear is assumed. The input data of 4 and 5 August 1968 have been chosen for the prediction experiment. Both days refer to the mature stage of a monsoon depression. Wind and temperature data are available at all standard pressure levels upto $100 \mathrm{mb}$, however there is no moisture observation beyond $500 \mathrm{mb}$ level. Since the specific humidity $(q)$ is required at $300 \mathrm{mb}$ also, this is computed using the relative humidity value of $500 \mathrm{mb}$ and the temperature of $300 \mathrm{mb}$. 


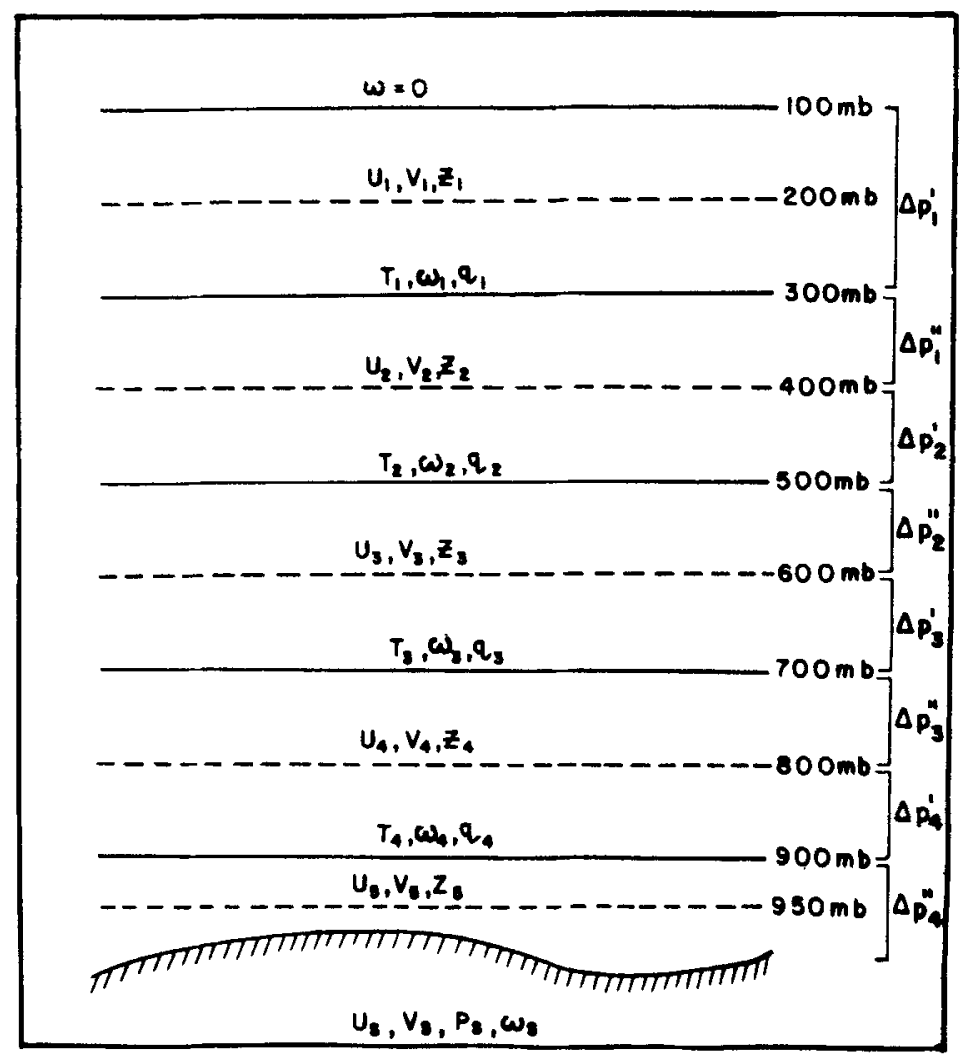

Figure 1. Vertical structure of five level primitive equation model.

In other words, no vertical variation in relative humidity beyond $500 \mathrm{mb}$ level is assumed. A time step of $5 \mathrm{~min}$ for the grid length chosen was found suitable.

\section{Boundary conditions}

Rigid walls are specified between two outermost rows of gridpoints in the north and south directions where the normal component of motion vanishes, but tangential flow is permitted. In the east-west direction cyclic continuity is adopted by extending the domain by eight additional grid points on the eastern side and the variables are specified as

$$
Q(L+8)=Q(2) \text { and } Q(1)=Q(L+7)
$$

where $L$ is the number of grid points in the east-west direction in the unextended domain and $Q$ stands for any variable such as $u, v$, etc. Data in the extended domain are obtained by fitting a cubic polynomial using values of grid points $L-1, L, L+7$ and $L+8$. The lateral boundary conditions are used to determine $u, v, T, q$, and $P_{s}$ at the 
outermost grid points using values of grid point inside. Following the above procedure the variables may be specified as follows at the north-south boundary,

$$
\frac{\partial u}{\partial y}=\frac{\partial T}{\partial y}=\frac{\partial q}{\partial y}=\frac{\partial p_{s}}{\partial y}=0 ; \quad \bar{v}^{y}=0,
$$

where $\bar{v}^{y}$ denotes the mean northward wind speed over the two outermost rows. For the evaluation of pressure tendency, $u_{s}$ and $v_{s}$ must be known. This is done by assuming zero wind shear between $950 \mathrm{mb}$ and the ground surface. Using the above criterion, wind at the lower boundary may be specified,

$$
u_{s}=u_{950}: \quad v_{s}=v_{950}
$$

\section{Finite difference scheme}

Following Okamura (1975), mass and energy conserving finite difference scheme for space derivatives has been adopted. We define the following two basic operators for finite differencing. The first operator is a finite difference form for the divergence of two physical quantities $A$ and $B$,

$$
\begin{aligned}
& D_{x}(A * B)_{i} \equiv \frac{1}{8 d \Delta p_{i}}\left[\left\{A_{i+1}\left(\Delta p_{i+1}+\Delta p_{i}\right)+A_{i}\left(3 \Delta p_{i}-\Delta p_{i-1}\right)\right\}\right. \\
& \left.\left(B_{i+1}+B_{i}\right)-\left\{A_{i-1}\left(\Delta p_{i-1}+\Delta p_{i}\right)+A_{i}\left(3 \Delta p_{i}-\Delta p_{i-1}\right)\right\}\left(B_{i}+B_{i-1}\right)\right],
\end{aligned}
$$

where $i$ denotes the grid point in the $x$-direction, $\Delta p_{i}$ the thickness of a layer in pressure difference, $d$ the grid interval, $D_{x}$ the finite difference with respect of $x$. It should be noted that the product $(A * B)$ is asymmetric on the right hand side of (9). A similar operator may be defined for $D_{y}$.

The second operator is expressed as

$$
G_{x}(A, B) \equiv \frac{1}{4 d}\left\{\left(A_{i+1}+A_{i}\right)\left(B_{i+1}-B_{i}\right)+\left(A_{i}+A_{i-1}\right)\left(B_{i}-B_{i-1}\right)\right\}
$$

This is the finite difference scheme for the product of $A$ and the derivative of $B$ with respect to $x$. A similar operator may be defined for $G_{y}$. The centred difference scheme using three data levels has been adopted for vertical derivatives.

These operators ensure the energy conservation property of the governing equations in the finite difference form. Applying (9) and (10) to (1) through (8), the finite difference equations of the model equations are obtained. For marching in time, the Leapfrog scheme with an Asselin (1972) time filter is adopted.

\section{Physical processes}

\subsection{Sub-grid scale horizontal diffusion}

Horizontal diffusion is introduced in the momentum, thermodynamic and water vapour equations. A simple linear diffusion formula is used in the model as,

$$
F_{\alpha}=v \nabla^{2} \alpha, \quad \alpha=u, v, T \text { or } q .
$$


The value of coefficient $v$ is determined following Leith (1969),

$$
v=\gamma|\nabla \zeta| d^{3}
$$

where $\zeta$ is relative vorticity, $d$ the grid distance, and $\gamma$ is the empirically determined nondimensional constant being set to 0.25 .

\subsection{Surface friction}

The exchange of momentum between the air and the earth's surface in the surface layer is expressed by the stress vector

$$
\tau=\rho C_{D}^{\prime}\left|\mathbf{V}_{m}\right| \mathbf{V}_{m}
$$

where $C_{D}^{\prime}=0.75 C_{D}^{\prime \prime}$ and $V_{m}$ is the wind vector at $Z=Z_{m}(=10 \mathrm{~m})$. The coefficient $C_{D}^{\prime \prime}$ (relation for computing $C_{D}^{\prime \prime}$ is given in $\$ 6.3$ ) is calculated over the sea surface. The coefficient over the land is set three times as large as the maximum value of $C_{D}^{\prime}$ over the sea surface. The following relation is used for stress at $900 \mathrm{mb}$ and above,

$$
\begin{aligned}
\tau_{900} & =\rho K m\left(\frac{\partial V}{\partial Z}\right)_{900} & & (p \geqslant 900 \mathrm{mb}), \\
\tau & =0 & & (p<900 \mathrm{mb})
\end{aligned}
$$

where $K m=l^{2}\left|\left(\frac{\partial \mathrm{V}}{\partial Z}\right)\right|_{900}$ and $l=30 \mathrm{~m}$.

\subsection{Surface exchange of sensible heat and moisture}

The exchange of heat and moisture is evaluated by the bulk method and over land is set as zero.

In the bulk method, sensible heat flux from the sea surface, $H_{0}$ may be given as

$$
H_{0}=\rho C_{D}^{\prime \prime} C_{p}\left|\mathbf{V}_{m}\right|\left(T_{0}-T_{a}\right)
$$

For an unstable and neutral case:

$$
\begin{aligned}
& \left(\Delta T=T_{0}-T_{a} \geqslant 0\right) \\
& C_{D}^{\prime \prime}=(1.0+0.066 \Delta T) \times\left(0.883+0.084\left|V_{m}\right|\right) \times 10^{-3}
\end{aligned}
$$

For a stable case:

$$
\begin{aligned}
& \Delta T=T_{0}-T_{a}<0 \\
& C_{D}^{\prime \prime}=(1.0+0.111 \Delta T) \times\left(0.889+0.055\left|\mathbf{V}_{m}\right|\right) \times 10^{-3},
\end{aligned}
$$

where $T_{0}$ is sea surface temperature and $T_{a}$ the temperature of the air at the altitude of $Z_{m}(10 \mathrm{~m})$.

Surface flux of water vapour (evaporation) is evaluated by the same formula as that of sensible heat

$$
W_{0}=\rho C_{D}^{\prime \prime}\left|\mathbf{V}_{m}\right|\left[q\left(T_{0}\right)-q\left(T_{a}\right)\right]
$$


where $q\left(T_{0}\right)$ and $q\left(T_{a}\right)$ are specific humidity at sea surface temperature $T_{0}$, and at air temperature $T_{a}$.

Vertical eddy diffusion of sensible heat and moisture is evaluated in the following way:

$$
\begin{aligned}
& H_{0}=0, \quad p<900 \mathrm{mb} \\
& W=-\rho K m \frac{\partial q}{\partial z}, \quad K m=l^{2}\left|\frac{\partial \mathrm{V}}{\partial z}\right|, \quad p \geqslant 700 \mathrm{mb}, \\
& W=0 . \quad p<700 \mathrm{mb}
\end{aligned}
$$

$H_{0}, C_{D}^{\prime \prime}$ and $W_{0}$ are computed following Electronic Computation Centre (1980).

\subsection{Dry convective adjustment}

Dry convective adjustment is performed wherever superadiabatic lapse rates $\left.(-\partial T / \partial p)>\gamma_{d}\right)$ were encountered. Following Kanamitsu (1975), the adjustment modifies the vertical temperature distribution while preserving the dry static energy.

\subsection{Large scale condensation and stable heating}

If the relative humidity reaches $100 \%$, large scale condensation is assumed to take place. The relative humidity is not allowed to exceed $100 \%$ as the excess water vapour is condensed instantaneously and humidity values are brought to their saturation values. Appropriate heating and humidity changes are introduced in the model equations following Manabe et al (1965). The scheme is briefly presented below.

The specific humidity $(\delta q)$ and temperature $(\delta T)$ are adjusted by solving the equation,

$$
\begin{aligned}
& q+\delta q=q_{s}(T+\delta T, p), \\
& C_{p} \delta T+L \delta q=0 .
\end{aligned}
$$

Iterative procedures for solving the above equations are adopted following Manabe et al (1965). The condensed rain for the entire column is given by

$$
P_{r}(\text { large scale })=-\frac{1}{g} \int_{100}^{p_{r}} \delta q \mathrm{~d} p .
$$

\subsection{Parametrization of cumulus convection}

The parametrization of cumulus convective scheme of Kuo $(1965,1974)$ modified by Kanamitsu (1975) and Krishnamurti et al (1976) has been invoked for computation of convective transport of heat and moisture. The large scale supply of moisture $I$ is defined by the relation,

$$
I=\frac{1}{g} \int_{P_{b}}^{P_{T}} \omega \frac{\partial q}{\partial p} \mathrm{~d} p
$$


where $P_{b}$ denotes the cloud base which is here identified with the lifting condensation level (LCL) and $P_{T}$ denotes the cloud top and is determined from an intersection of the local moist adiabat (through LCL) with the environmental sounding in the upper troposphere.

$I$ is partitioned into

or

$$
I=I_{\theta}+I_{q} \text {, }
$$

where $I_{\theta}$ is the part of the moisture supply which goes into enhancing the temperature field and $I_{q}$ is a part that modifies the moisture field and $b$ is the fraction of available moisture supply that modifies the moisture field. Two other quantities $Q_{\theta}$ and $Q_{q}$ are determined by the relations

$$
\begin{aligned}
& Q_{\theta}=-\frac{C_{p}}{L g} \int_{P_{B}}^{P_{T}}\left[\left(\frac{T_{s}-T}{\Delta t}\right)+\frac{T}{\theta} \omega \frac{\partial \theta}{\partial p}\right] \mathrm{d} p \\
& Q_{q}=-\frac{1}{g} \int_{P_{B}}^{P_{T}}\left(\frac{q_{s}-q}{\Delta t}\right) \mathrm{d} p
\end{aligned}
$$

Here $\Delta t$ denotes the cloud time scale. These two quantities $Q_{\theta}$ and $Q_{q}$ are known and $Q=Q_{\theta}+Q_{q}$ is a measure of total moisture supply needed to cover a volume over a horizontal area with clouds. The two unknowns $a_{\theta}$ and $a_{q}$ for (11) and (12) are defined by the relations,

$$
\begin{aligned}
& a_{\theta}=I_{\theta} / Q_{\theta}, \\
& a_{q}=I_{q} / Q_{q} .
\end{aligned}
$$

Following Kuo (1965), the convective heating and moisture transport by convection at each level is expressed as follows:

$$
\begin{aligned}
& \frac{\partial \theta}{\partial t}=-\omega \frac{\partial \theta}{\partial p}+a_{\theta}\left[\omega \frac{\partial \theta}{\partial p}+\frac{\theta}{T}\left(\frac{T_{s}-T}{\Delta t}\right)\right], \\
& \frac{\partial q}{\partial t}=a_{q}\left(\frac{q_{s}-q}{\Delta t}\right)
\end{aligned}
$$

and $\quad \int \frac{C_{p} T}{L \theta} \frac{\partial \theta}{\partial t} \mathrm{~d} p=A+(1-b) I$,

$$
\int \frac{\partial q}{\partial t} \mathrm{~d} p=b I,
$$

where $\quad A=-\frac{1}{g} \int \frac{C_{p}}{L} \frac{T}{\theta} \omega \frac{\partial \theta}{\partial p} \mathrm{~d} p$

In the prediction model, the cumulus scale heating and vertical flux of moisture are invoked only if the sounding is conditionally unstable and the net large scale convergence of flux of moisture in the vertical column is positive. In order to determine 
$b,(13)$ and (14) are equated to close the system. Thus,

$$
\begin{aligned}
& b=(A+I) / 2 I, \\
& a_{q}=(A+I) / 2 Q_{q}, \\
& a_{\theta}=(I-A) / 2 Q_{\theta} .
\end{aligned}
$$

The cloud time scale, $\Delta t$ is set equal to $30 \mathrm{~min}$ in this experiment.

\section{Initialization}

The simplest initialization procedure for the primitive equation model is to balance mass and motion fields through a nonlinear balance equation. In this method geopotentials are obtained from nondivergent wind through a reverse balance equation and temperature is derived through hydrostatic relation. Vertical motion and horizontal divergence are set to zero initially. Singh and Saha (1976) and Singh (1977) applied this scheme of initialization to predict a case of monsoon depression and of tropical cyclone. Round-the-clock forecast movement of cyclonic circulation and flow patterns were reasonably good; but the temperature lapse rate in the initial and forecast fields were far from satisfactory mainly due to poor boundary conditions for the solution of the balance equation.

Kanamitsu (1975) and Kiangi (1977) showed that the dynamic initialization is superior to static initialization (balance equation solution) for the initial adjustment of mass and motion fields for the tropical atmosphere. The success of dynamic initialization experiment (Singh et al 1980) for the barotropic prediction of monsoon depression and the failure to obtain the realistic temperature and vertical velocity fields in an earlier version of the model (Singh and Saha 1976) motivated us to apply the dynamic initialization scheme for the present study. The formulation is essentially the same as that followed by Winninghoff (1973) and Kanamitsu (1975).

For the application of dynamic initialization the variables $u, v, T, q, P_{s}$ are needed as inputs to the model. The observed wind field is initially modified so that the vertical motion at the lowest level of the model vanishes. This step is necessary to suppress the external gravity waves, at least initially and is called pre-initialization.

\subsection{Pre-initialization}

(i) From the observed wind, the stream function $(\psi)$ and nondivergent part of wind $u_{\psi}$ and $v_{\downarrow}$ at each level are evaluated by the relation

$$
\begin{aligned}
& \nabla^{2} \psi=m^{2}\left[\frac{\partial}{\partial x}\left(\frac{v_{\mathrm{ob}}}{m}\right)-\frac{\partial}{\partial y}\left(\frac{u_{\mathrm{ob}}}{m}\right)\right], \\
& u_{\psi}=-m \frac{\partial \psi}{\partial y}, \quad v_{\psi}=m \frac{\partial \psi}{\partial x} .
\end{aligned}
$$

(ii) The horizontal divergence from the observed wind at each level is computed. The divergence is adjusted such that the net divergence in a vertical column vanishes. Since the net divergence computed from the observed wind may not vanish, the correction in 
the divergence field is applied at levels where observations and analyses are not considered the best. The $200,800 \mathrm{mb}$ and surface levels are considered the best quality levels due to the large number of surface observations, pibal observations, commercial aircraft reports and satellite cloud motion vectors and as such the correction is applied only at 400 and $600 \mathrm{mb}$ levels; at $200,800 \mathrm{mb}$ and surface levels the divergence is fixed. This is done through the following relation

$$
(\nabla \cdot V)_{k}^{\text {corrected }}=(\nabla \cdot V)_{k}^{\text {observed }}-\beta_{k} /\left(\sum_{k=1}^{N} \beta_{k} \Delta p_{k}\right) \sum_{k=1}^{N} \Delta p_{k}(\nabla \cdot V)_{k}^{\text {observed }},
$$

where $\Delta p$ is the pressure difference between the two wind levels, $k$ is the subscript for level and $\beta_{k}=1$ for 400 and $600 \mathrm{mb}$ and zero for $200,800 \mathrm{mb}$ and surface levels.

From the adjusted divergence the irrotational part of wind is evaluated as

$$
\begin{aligned}
& \nabla^{2} \chi=\nabla \cdot V \\
& u_{x}=m \frac{\partial \chi}{\partial x}, \quad v_{x}=m \frac{\partial \chi}{\partial y} .
\end{aligned}
$$

(iii) The adjusted wind is computed as

$$
\begin{aligned}
& u_{\mathrm{adj}}=u_{\psi}+u_{x}, \\
& v_{\mathrm{adj}}=v_{\psi}+v_{x} .
\end{aligned}
$$

The geopotential height $(z)$ is computed from the surface pressure and the observed temperature

$$
\partial z / \partial p=-R T_{v} / p g
$$

Thus, all variables $u, v, T, q, z$ and $P_{s}$ are known initially.

\subsection{Dynamic initialization}

The common method for obtaining the balanced field through a dynamic initialization scheme is to insert the data for dominant variables into the prognostic equations and integrate back and forth around the initial time, applying a time differencing scheme which tends to suppress the gravity waves but does not affect meteorological component significantly. In the present study, a scheme suggested by Temperton (1976) has been applied. For a typical variable $u$, one iteration of the scheme is defined by

$$
\begin{aligned}
& u^{*}=u^{(v)}+\Delta t\left(\frac{\partial u}{\partial t}\right)^{(v)}, \\
& u^{* *}=u^{*}-\Delta t\left(\frac{\partial u}{\partial t}\right)^{*}, \\
& u^{v+1}=3 u^{(v)}-2 u^{* *}
\end{aligned}
$$

where $v$ is the iteration number. It can be shown that in one cycle of iteration a wave of frequency is damped by a factor $1-2 \Delta t^{2} K^{2} \sigma^{2}$. The wave of frequency $K \sigma= \pm 1 /(2)^{1 / 2} \Delta t$ will be completely removed after one cycle, while higher frequency waves will change sign at each iteration. 
Although it is desirable to force the mass field to adjust towards wind field, in this experiment no consideration is given to the restoration of any variable and all fields are left free to adjust mutually. The iteration scheme (15) is applied for marching back and forth with $\Delta t$ positive for odd cycles, which is replaced by $-\Delta t$ for even cycles. The diabatic heating is not incorporated during initialization, although the moisture continuity equation is included for temperature correction. There is very little chance for supersaturation to occur, however if such situation occurs, the excess moisture is removed without effecting any change in the temperature. During the present experiment such a situation did not occur at any grid point.

One step forward as given by (15) and one step backward with $\Delta t=-\Delta t$ constitutes one cycle of iteration. In this experiment ninety such cycles are performed to achieve the initial balance. The number of cycles is chosen arbitrarily as there is no theoretical criterion for achieving the convergence except that root mean square difference for basic fields $\left(u, v, T\right.$ and $\left.P_{s}\right)$ of two successive iterations with an interval of 10 cycles become exceedingly small.

\section{Results of initialization experiment}

Initialization and forecast results with the input of 4 and 5 August have been found to be similar; hence the results of only one input day i.e. 5 August will be presented and discussed. However, results of 4 August will also be discussed where it is relevant.

Table 1 which presents the root mean square difference for basic fields of two successive iterations, shows that at the end of the initialization experiment the rate of reduction is very slow.

Figures 2, 3, 4 and 5 present fields before and after the initialization of the surface pressure, wind at 800 and $200 \mathrm{mb}$, temperature at 700 and $300 \mathrm{mb}$, and vertical velocity at 700 and $300 \mathrm{mb}$ respectively.

It may be seen from figures 2 through 5 that initialization smoothens the patterns of all variables. Maximum changes are noticed in the surface pressure; even the geometry of the circulation system is either lost or completely modified. Kanamitsu (1975) also

Table 1. Koot mean square difference between successive iterations (interval of 10 cycles)

\begin{tabular}{|c|c|c|c|c|c|c|c|c|c|c|c|c|c|c|c|}
\hline \multirow[t]{2}{*}{$\begin{array}{l}\text { Cycle } \\
\text { No. }\end{array}$} & \multicolumn{2}{|c|}{$P_{s}(\mathrm{mb})$} & \multicolumn{4}{|c|}{$u\left(\mathrm{~ms}^{-1}\right)$} & \multicolumn{5}{|c|}{$v\left(\mathrm{~ms}^{-1}\right)$} & \multicolumn{4}{|c|}{$T\left({ }^{\circ} \mathbf{K}\right)$} \\
\hline & & 950 & 800 & 600 & 400 & 200 & 950 & 800 & 600 & 400 & 200 & 900 & 700 & 500 & 300 \\
\hline 10 & 1.44 & 0.12 & 0.12 & 0.12 & 0.15 & 0.29 & $0-16$ & 0.16 & 0.15 & 0.18 & 0.49 & 0.06 & 0.08 & $0-08$ & 0.12 \\
\hline 20 & 0.57 & 0.08 & 0.08 & $0-06$ & 0.06 & 0.18 & 0.12 & 0.11 & $0-09$ & $0-07$ & 0.31 & $0-03$ & $0-04$ & 0.05 & $0-09$ \\
\hline 30 & 0.33 & $0-07$ & $0-07$ & 005 & 005 & 0.14 & $0 \cdot 10$ & 0.10 & 0.08 & $0-06$ & 0.26 & 0.02 & $0-03$ & $0-04$ & $0-08$ \\
\hline 40 & $0-23$ & 0.07 & 0.06 & 0.05 & 0.04 & 0.12 & 0.10 & $0-09$ & 007 & 005 & 0.22 & $0-01$ & $0-03$ & 0.04 & 0.07 \\
\hline 50 & 0.18 & $0-06$ & 005 & $0-04$ & 0.04 & 0.10 & $0-09$ & 008 & 0.06 & $0-04$ & $0 \cdot 19$ & 001 & 0.03 & 0.03 & 0.06 \\
\hline 60 & 0.14 & 006 & 0.05 & $0-04$ & 004 & 009 & 008 & $0-07$ & 0.06 & 0.04 & 0.17 & $0-01$ & 002 & 0.03 & 0.05 \\
\hline 70 & 0.12 & 0.05 & 0.05 & 0.03 & 004 & 0.08 & 0.07 & 006 & 0.05 & 004 & 0.16 & 0.01 & 0.02 & 0.03 & 0.05 \\
\hline 80 & 0.10 & 0.05 & 0.04 & $0-03$ & $0-03$ & $0-07$ & 007 & $0-06$ & $0-05$ & $0-03$ & 0.14 & 001 & 0.02 & 0.03 & 005 \\
\hline 90 & 0.09 & 0.05 & $0-04$ & $0-03$ & 0.03 & $0-06$ & 006 & 005 & $0-04$ & 003 & 0.13 & $0-01$ & 0.02 & 0.02 & 004 \\
\hline
\end{tabular}



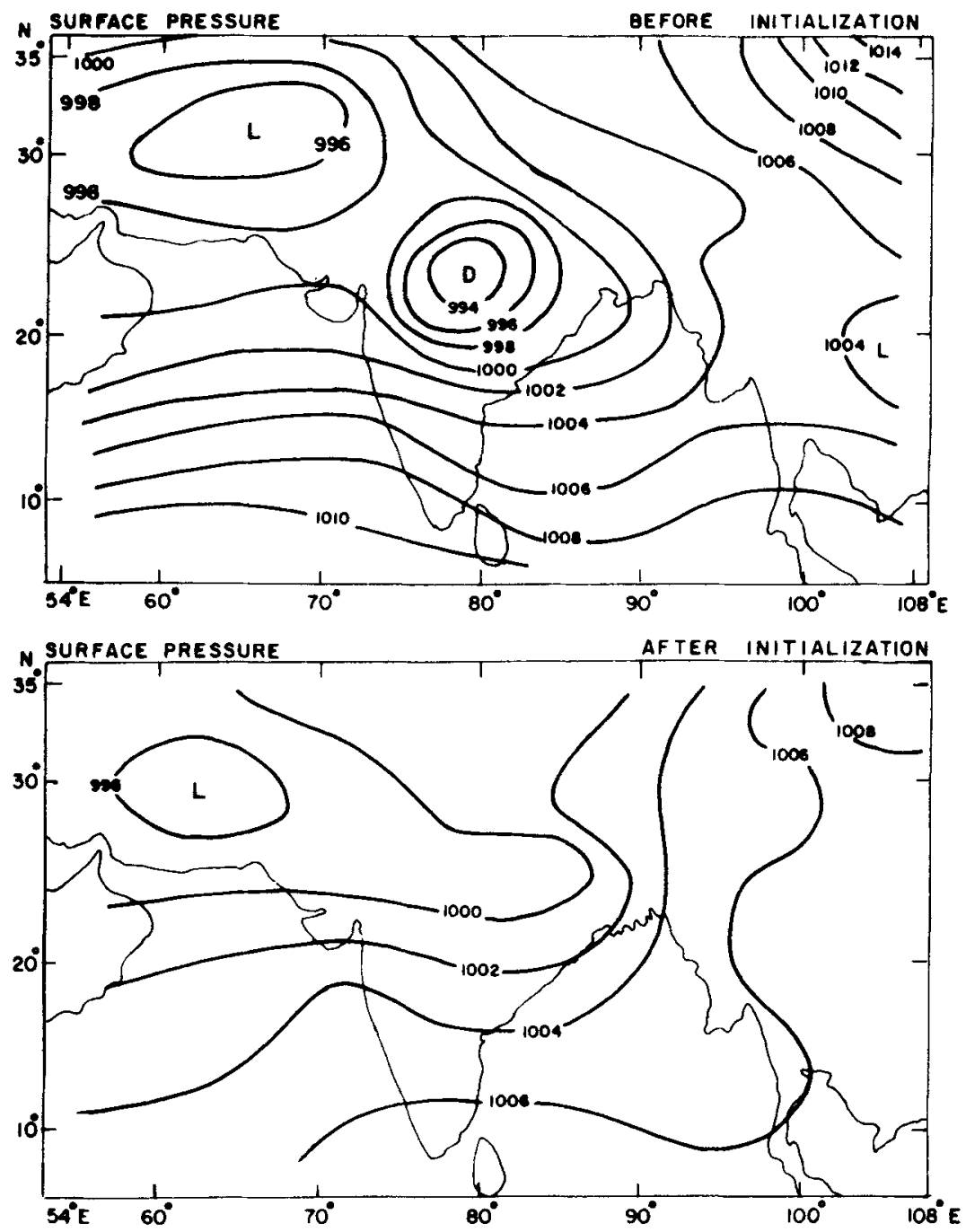

Figure 2. Change of surface pressure by initialization (unit: mb).

found similar results in his dynamic initialization experiment. Adjustment of surface pressure is not only affected by the surface wind but also by the vertically integrated divergence. The change in the surface pressure is obviously the reflection of adjustment of external gravity waves. Figures 3 and 4 and table 2 reveal that other variables like wind and temperature change very little after initialization. The insignificant change in temperature is the reflection of slight adjustment of internal gravity waves.

The vertical velocity patterns (figure 5) are considerably smoothed out without changing the basic patterns. Emergence of large vertical velocity values even after initialisation suggests the importance of the divergent part of the wind in the initial data of the monsoon region particularly for the input to the numerical model. 

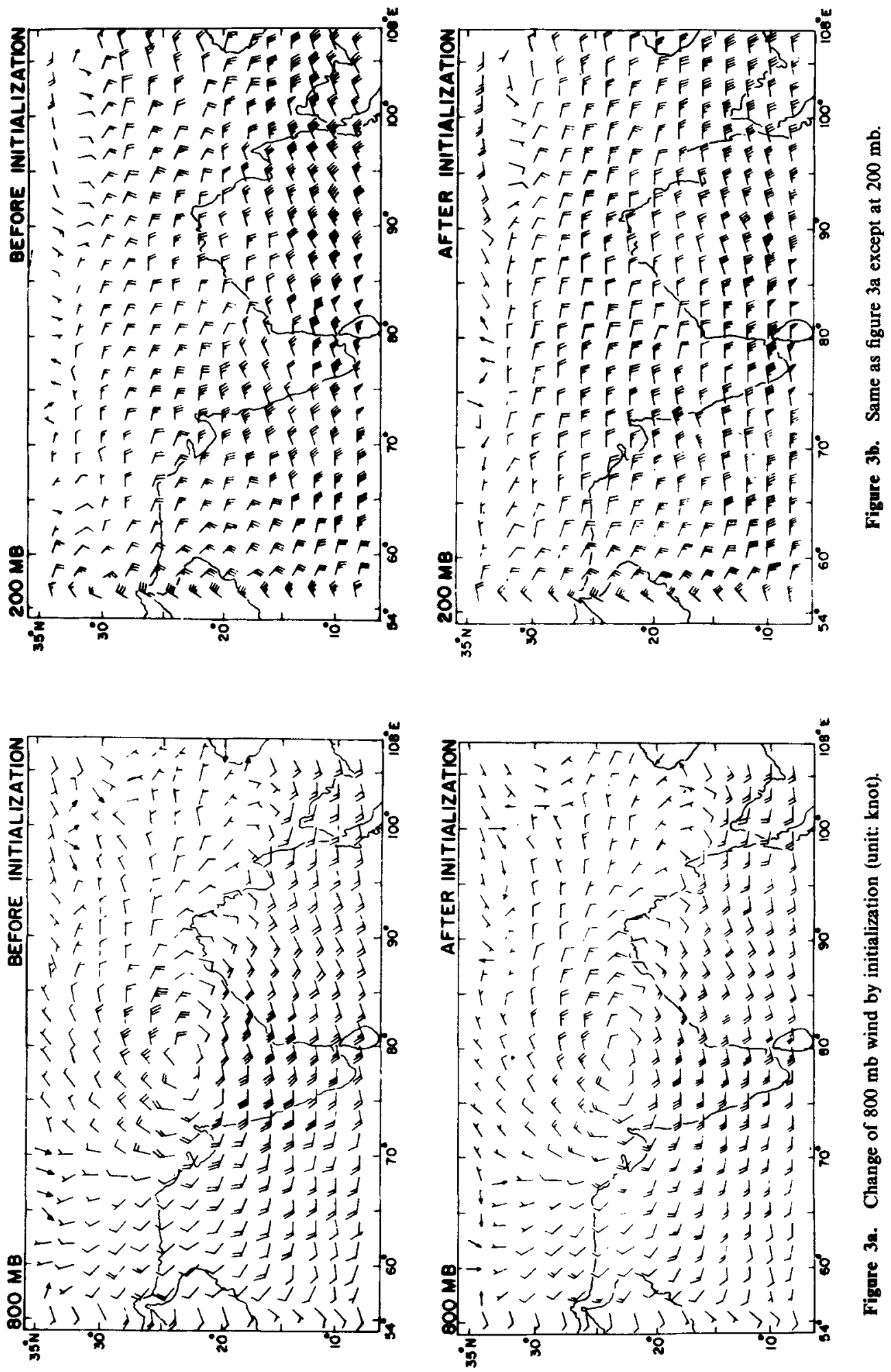
Prediction with primitive equation model
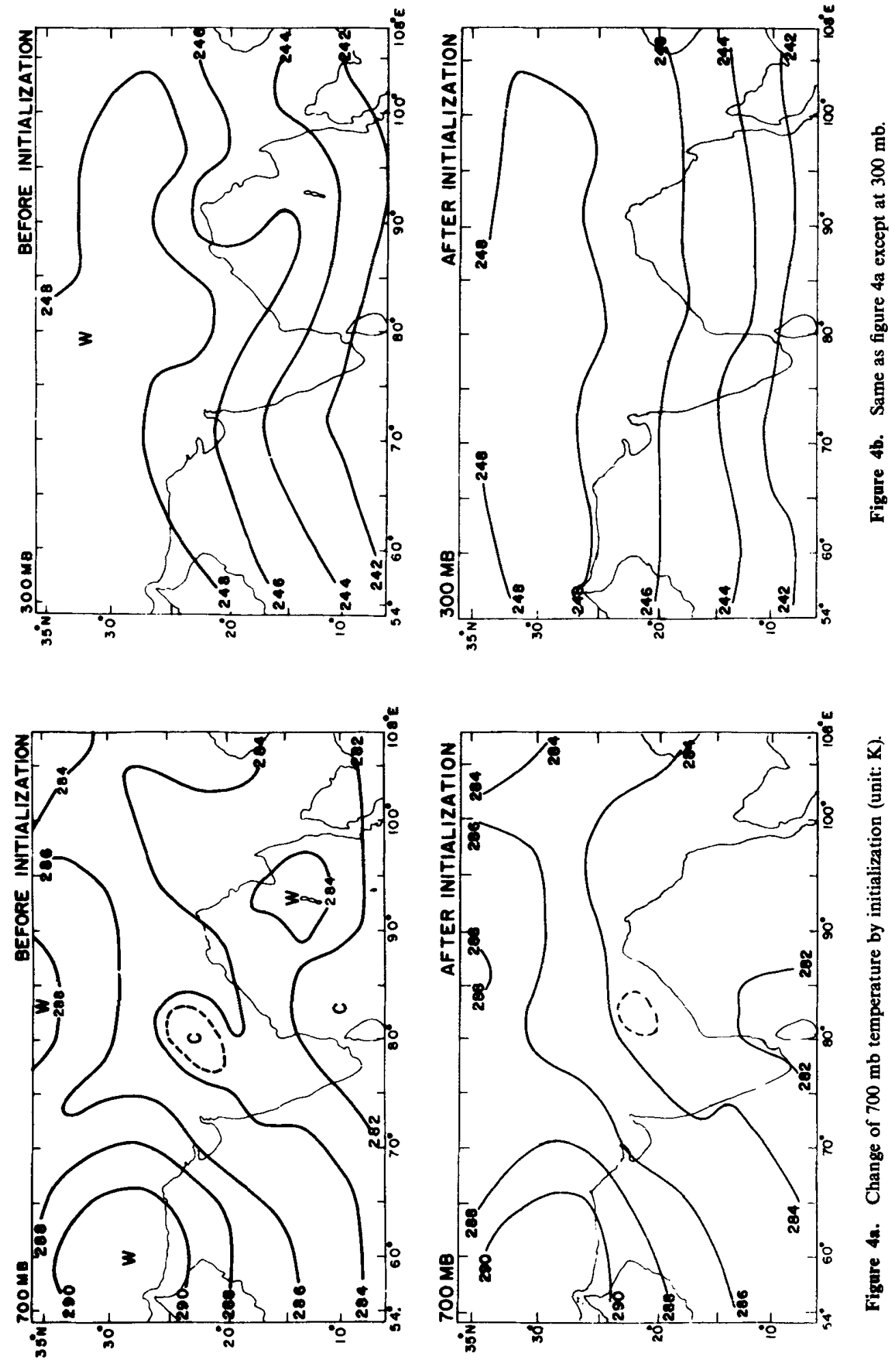

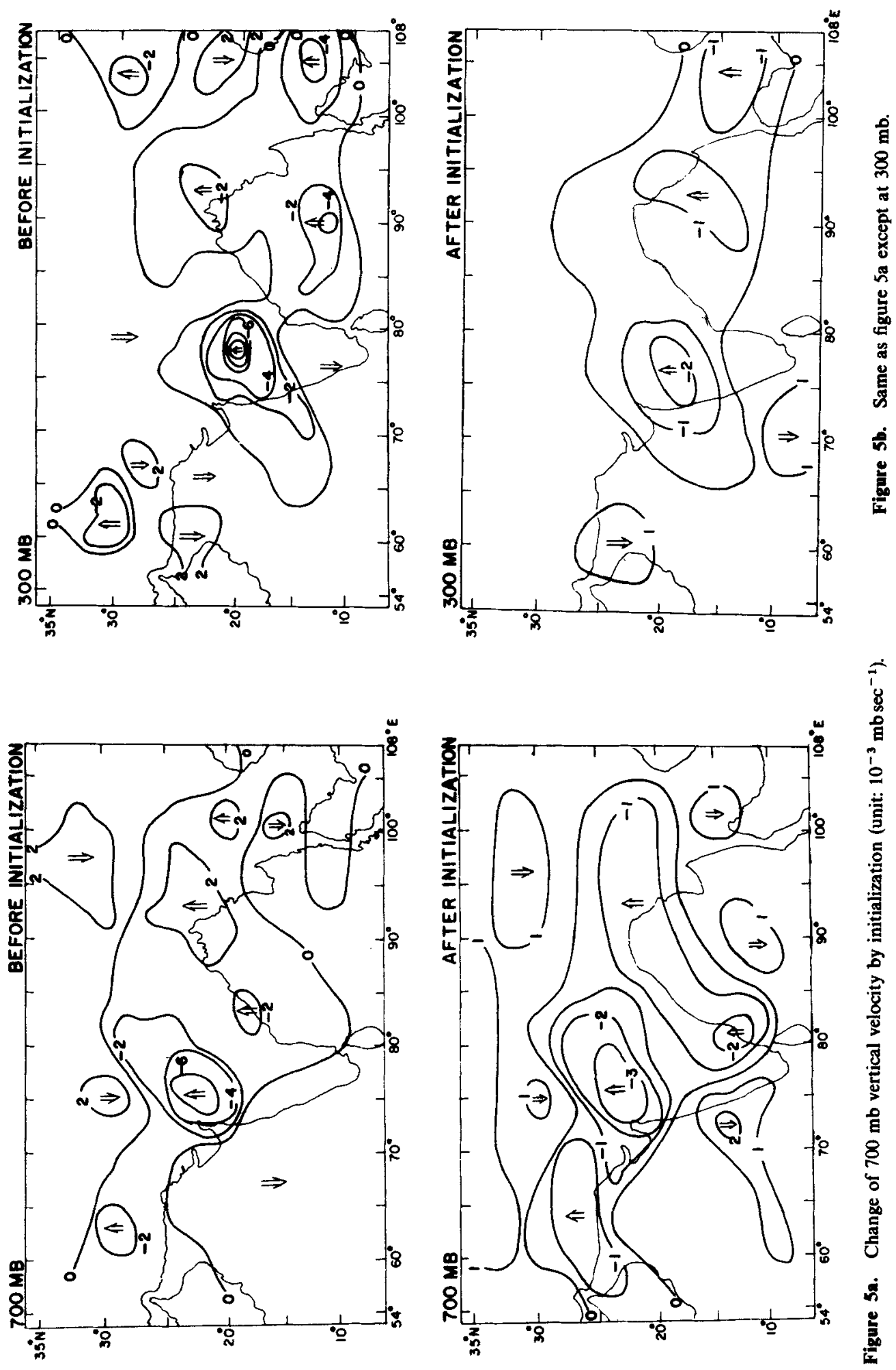
Table 2. Root mean square difference (RMs) between the fields before and after the iterative initialization

\begin{tabular}{lccccc}
\hline Variables & $\begin{array}{c}\text { Pressure } \\
\text { levels }\end{array}$ & $\begin{array}{c}\text { RMS } \\
\text { difference }\end{array}$ & Variables & $\begin{array}{c}\text { Pressure } \\
\text { levels }\end{array}$ & $\begin{array}{c}\text { RMs } \\
\text { difference }\end{array}$ \\
\hline$P_{z}$ & $\begin{array}{c}\text { Surface } \\
u\end{array}$ & $2.97 \mathrm{mb}$ & $v$ & 400 & $0.22 \mathrm{~ms}^{-1}$ \\
$v$ & 950 & $0.25 \mathrm{~ms}^{-1}$ & $u$ & 200 & $0.52 \mathrm{~ms}^{-1}$ \\
$u$ & 950 & $0.33 \mathrm{~ms}^{-1}$ & $v$ & 200 & $0.88 \mathrm{~ms}^{-1}$ \\
$v$ & 800 & $0.23 \mathrm{~ms}^{-1}$ & $T$ & 900 & $0.14^{\circ} \mathbf{K}$ \\
$u$ & 800 & $0.30 \mathrm{~ms}^{-1}$ & $T$ & 700 & $0-22^{\circ} \mathrm{K}$ \\
$v$ & 600 & $0.18 \mathrm{~ms}^{-1}$ & $T$ & 500 & $0.25^{\circ} \mathbf{K}$ \\
$u$ & 600 & $0.25 \mathrm{~ms}^{-1}$ & $T$ & 300 & $0.33^{\circ} \mathbf{K}$ \\
\hline
\end{tabular}

\section{Forecast results}

The model has been integrated upto $48 \mathrm{hr}$ with the input of 4 and 5 August 1968. As mentioned earlier the results of 5 August only will be presented. As considerable damping is noticed in the $\mathbf{4 8} \mathrm{hr}$ forecast, the details of the $\mathbf{2 4} \mathrm{hr}$ forecast are presented and discussed below; wherever necessary, the $48 \mathrm{hr}$ results will also be discussed. Figures 6 and 7 depict the $24 \mathrm{hr}$ forecast and corresponding verification charts in respect of wind at 800 and $200 \mathrm{mb}$ and temperature at 700 and $300 \mathrm{mb}$ respectively. Figure 8 gives the $24 \mathrm{hr}$ forecast and corresponding verification charts in respect of the vertical velocity field at $700 \mathrm{mb}$. It may be seen from figure 6 that the forecast flow patterns and movement of the cyclonic system have been found reasonably good. The temperature field as seen from figure 7 is very well predicted at $300 \mathrm{mb}$; however prediction at $700 \mathrm{mb}$ is not good. The upward vertical velocity maximum (figure 8) as expected is found in the western sector of the cyclonic system. The verification vertical velocity is computed from the observed divergence and as such it differs from the forecast vertical velocity. The difference is not merely due to inaccuracy in the forecast but also due to inherent errors in the computation of verification of vertical velocity from the observed divergence.

\subsection{The depression track}

Figure 9 depicts the tracks observed and predicted by one-level and five-level primitive equation models. The $\mathbf{2 4} \mathrm{hr}$ forecast position of the centre of the depression is slightly better in the five-level primitive equation model; however the movement as seen in $48 \mathrm{hr}$ is slower than the actual; it is also slower than that of barotropic prediction. Generally, the movement of the advecting system is very small as predicted by the barotropic model. Besides, the author has tested the movements of several depressions on the basis of the barotropic model and he finds the movement in the case of this series (4 to 6 August) is best predicted. Furthermore, the slower prediction movement after $24 \mathrm{hr}$ (in the five-level model) may partly be attributed to the complete absence of orography from the model. It is well known that bottom topography can produce faster westward movement of the monsoon depression (Krishnamurti et al 1977). The effects of 
orography on the westward movement are being investigated and would be reported later.

9.2 Vertical cross-sections of meridional wind, relative vorticity, temperature anomaly and vertical velocity along a zonal plane passing through $22^{\circ} \mathrm{N}$

9.2a Meridional wind: Figure 10 presents the observed and the predicted crosssections of the meridional wind along a zonal plane passing through $22^{\circ} \mathrm{N}$. The predicted northerly and southerly maxima coincide very well with the observed field. Furthermore, the eastward vertical tilt in the lower troposphere and the vertical extent of the cyclonic circulation are very well predicted. The separation distance between northerly and southerly maxima nearly coincide on 5 August; however, this distance is increased in the forecast field on 6 August suggesting broadening of the size of the depression.

9.2b Relative vorticity: The observed and the predicted relative vorticity crosssections are illustrated in figure 11 . The vorticity maximum is seen centred over the storm in the lower troposphere as expected. The vorticity maximum and its centre are very well predicted by the model, except that the predicted centre of the maximum lies slightly at a higher level than the observed. In general, the model has produced a good forecast of the vorticity field over the storm.

9.2c Temperature anomaly: The observed and the predicted vertical cross-sections of the temperature anomaly (difference from zonal mean) are presented in figure 12. The cold core in the lower troposphere is very well predicted although strong and slightly east of the actual location. The warm core above the storm in the upper troposphere is very well simulated by the model.

9.2d Vertical velocity: Figure 13 presents the predicted vertical cross-section of the vertical velocity. It may be seen that the maximum upward motion is centred over the storm in the middle troposphere as expected. Though the model has been successful in the prediction of vertical velocity, intensity has been found slightly weaker than usually expected $\left(3-4 \mathrm{mb} \mathrm{S}^{-1}\right)$ in the intense depression.

\subsection{Rainfall rates}

The $24 \mathrm{hr}$ predicted versus observed rainfall is presented in figure 14. The total rainfall includes the convective and stable precipitation. It may be seen that the most intense rainfall occurs slightly west of the storm centre which has been predicted reasonably well by the model. Furthermore, the region of precipitation is also handled very well by the model. However, the amount in general is very much underestimated (one fifth of the actual). The reasonably good prediction of rainfall rates mainly depend on moisture analyses in the lower troposphere, distribution of vertical velocity, parametrization of cumulus convection and horizontal and vertical resolutions of the model. It is likely iat most of the factors outlined above must have contributed to the poor prediction of rainfall rates. We are looking forward to improvement in prediction of rainfall rates in our future experiments. 

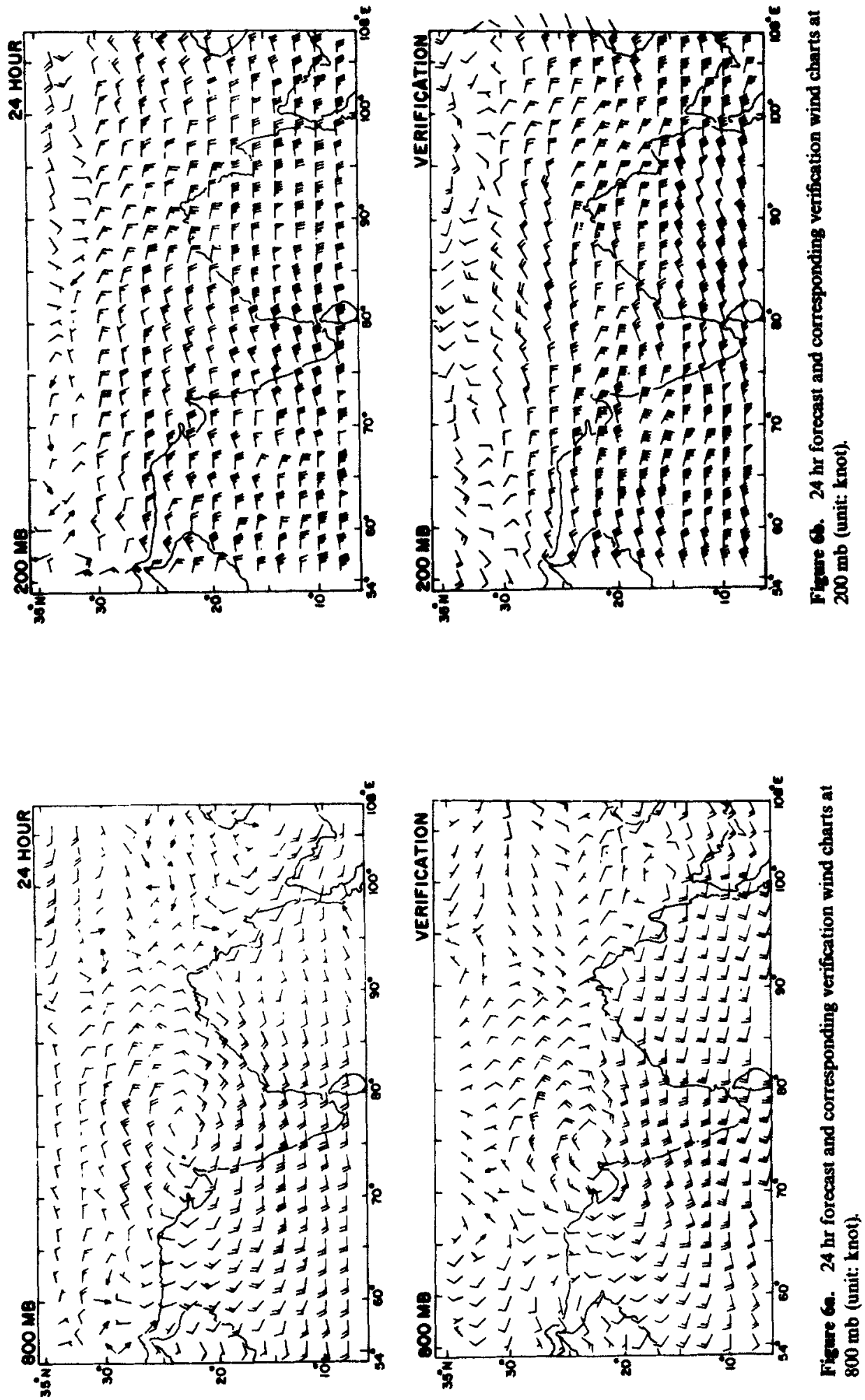

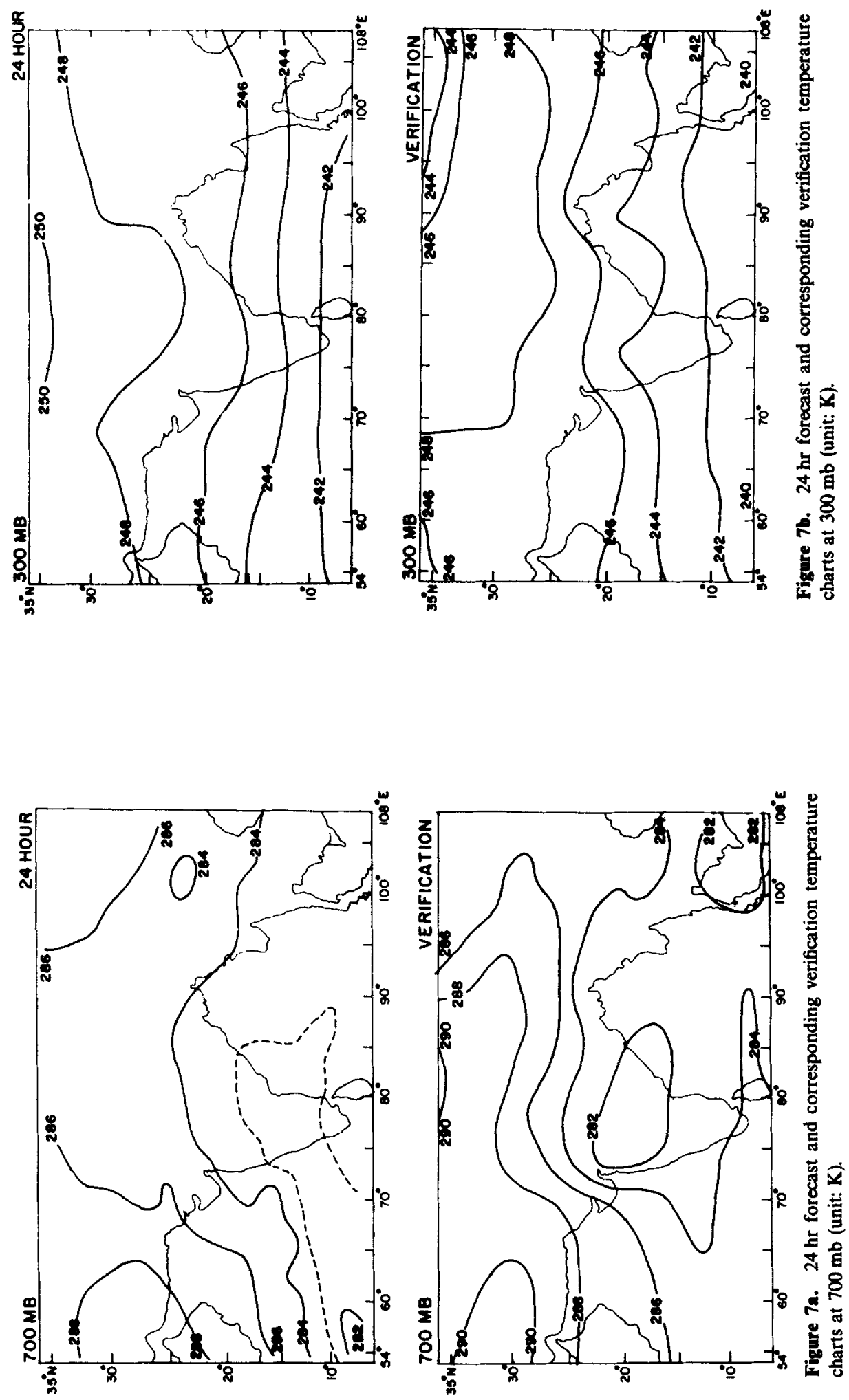

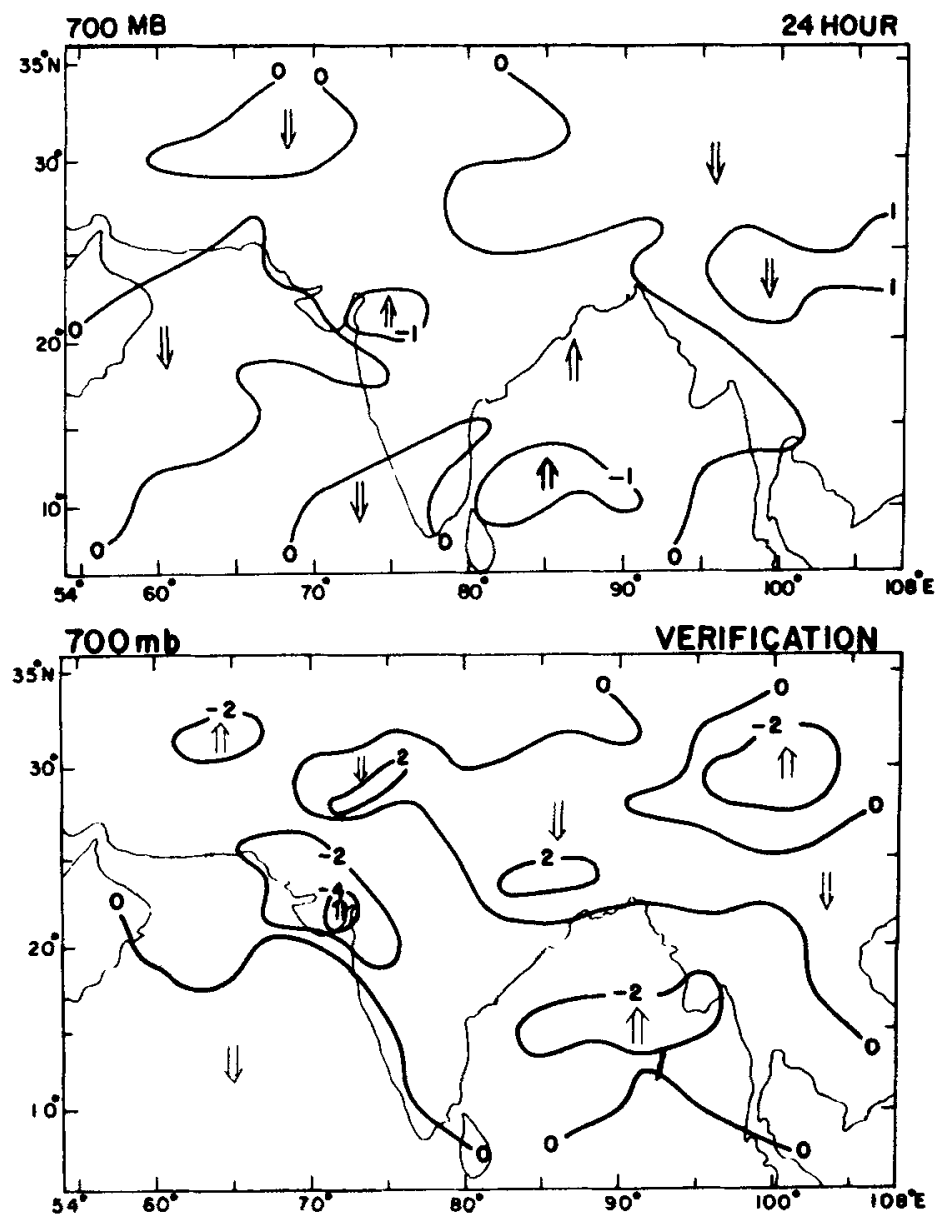

Figure 8. $24 \mathrm{hr}$ forecast and corresponding verification vertical velocity chart at $700 \mathrm{mb}$ (unit: $10^{-3} \mathrm{mb} \mathrm{S}^{-1}$ ).

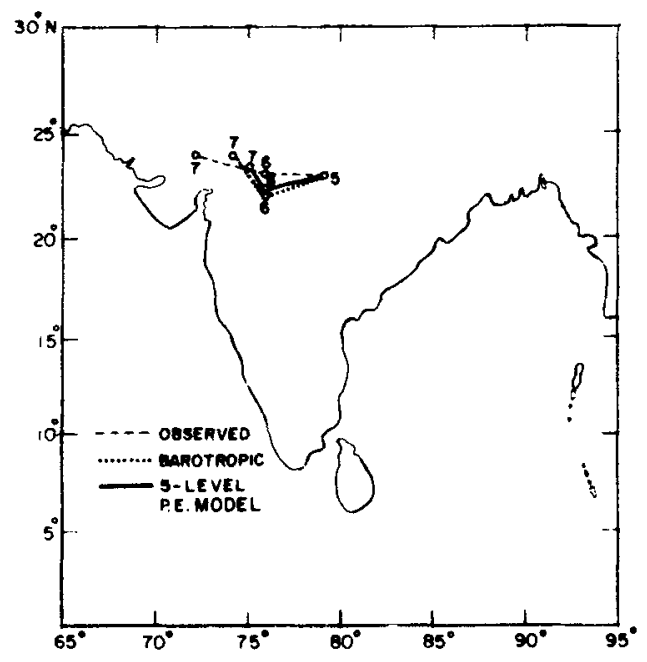

Figure 9. Observed versus predicted tracks in two different numerical prediction experiments. 

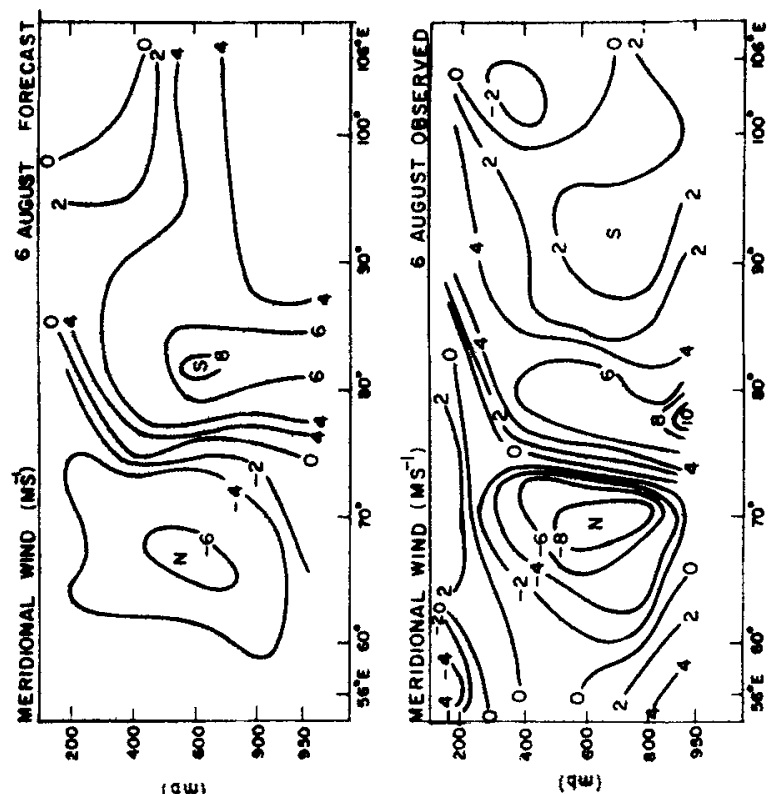

ह
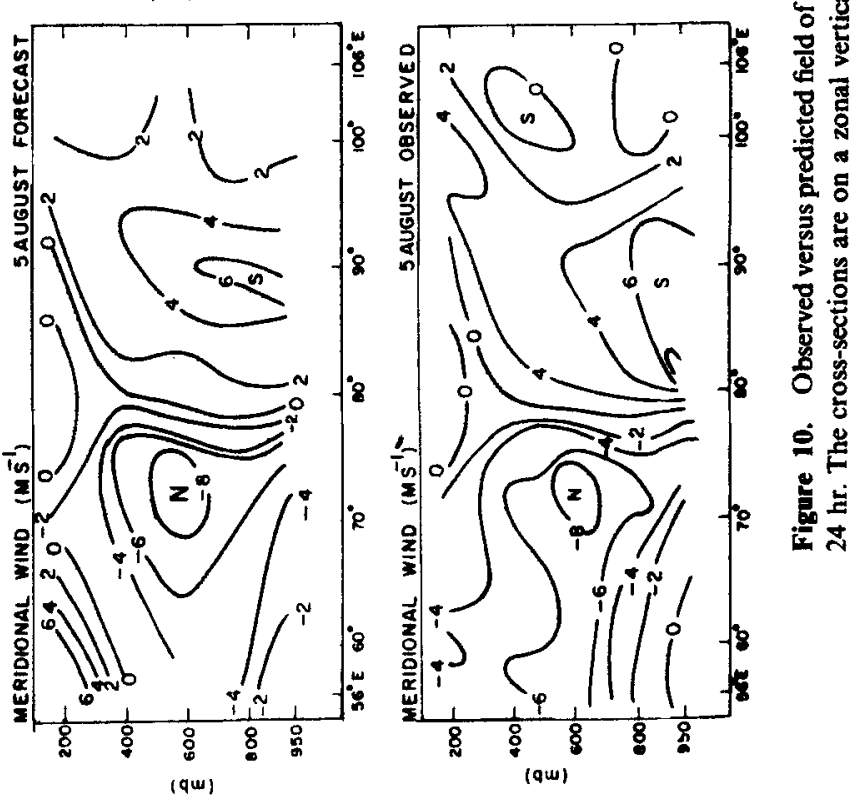

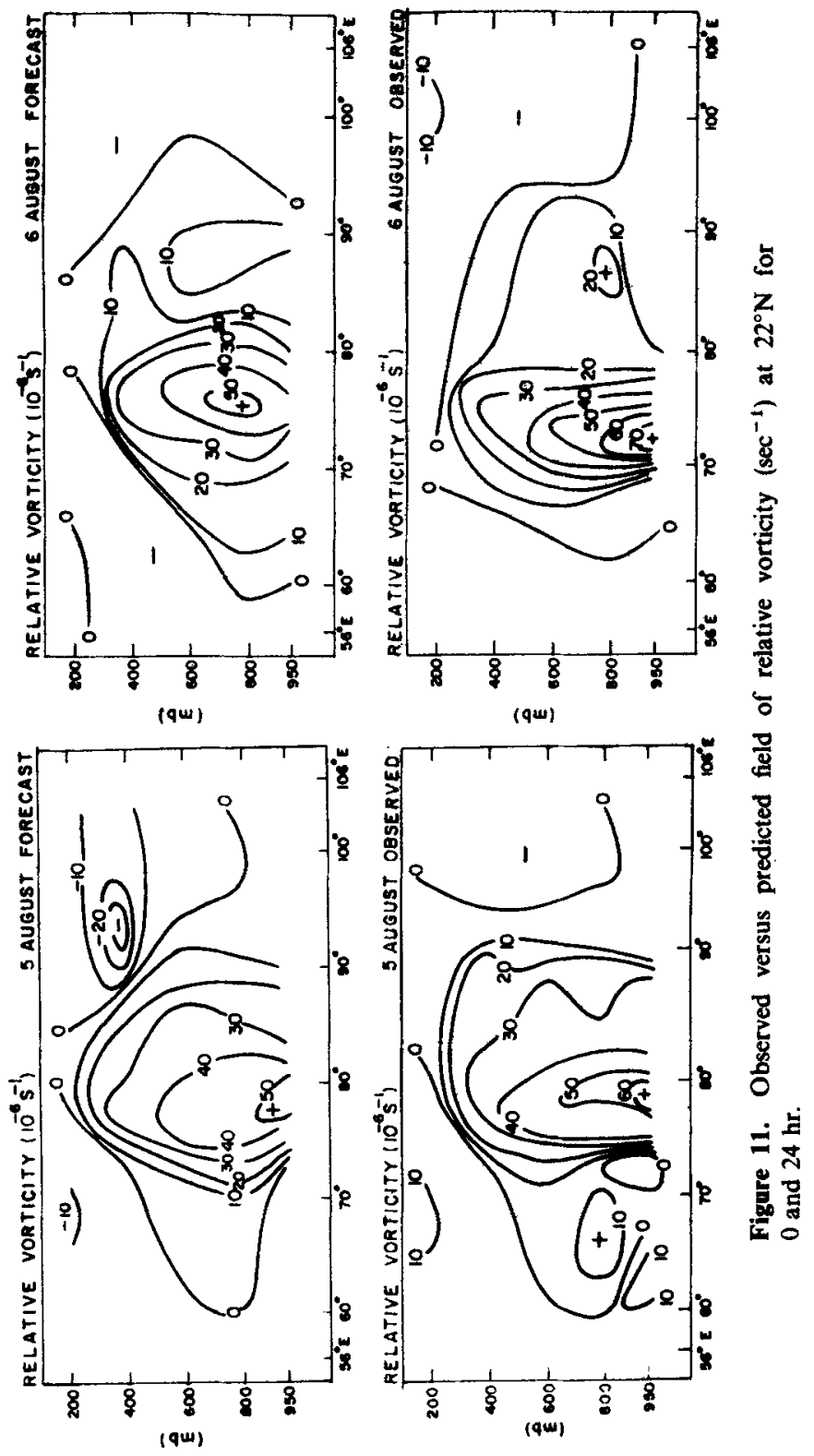

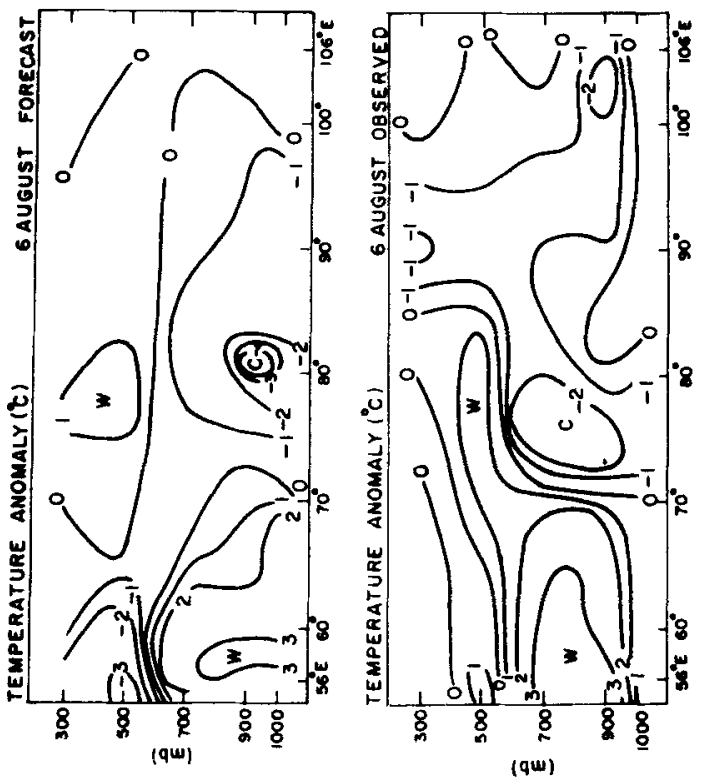

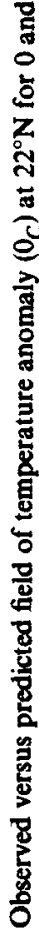
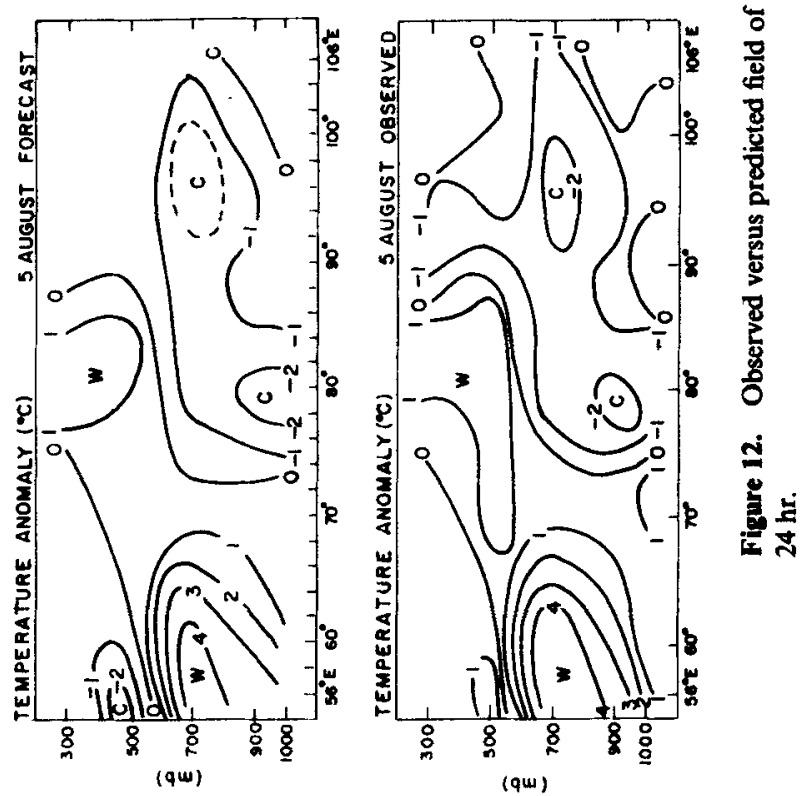


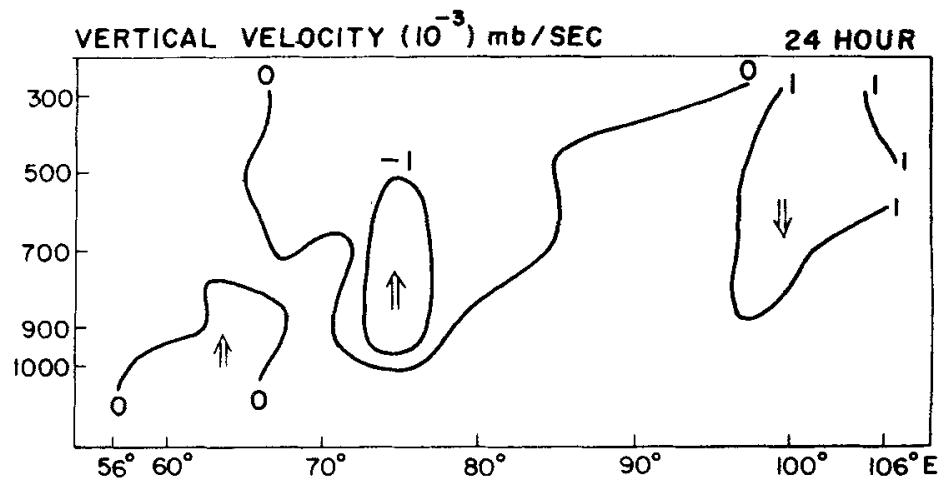

Figure 13. Predicted field of vertical velocity $\left(10^{-3} \mathrm{mb} \mathrm{sec}^{-1}\right)$ at $22^{\circ} \mathrm{N}$ for $24 \mathrm{hr}$.
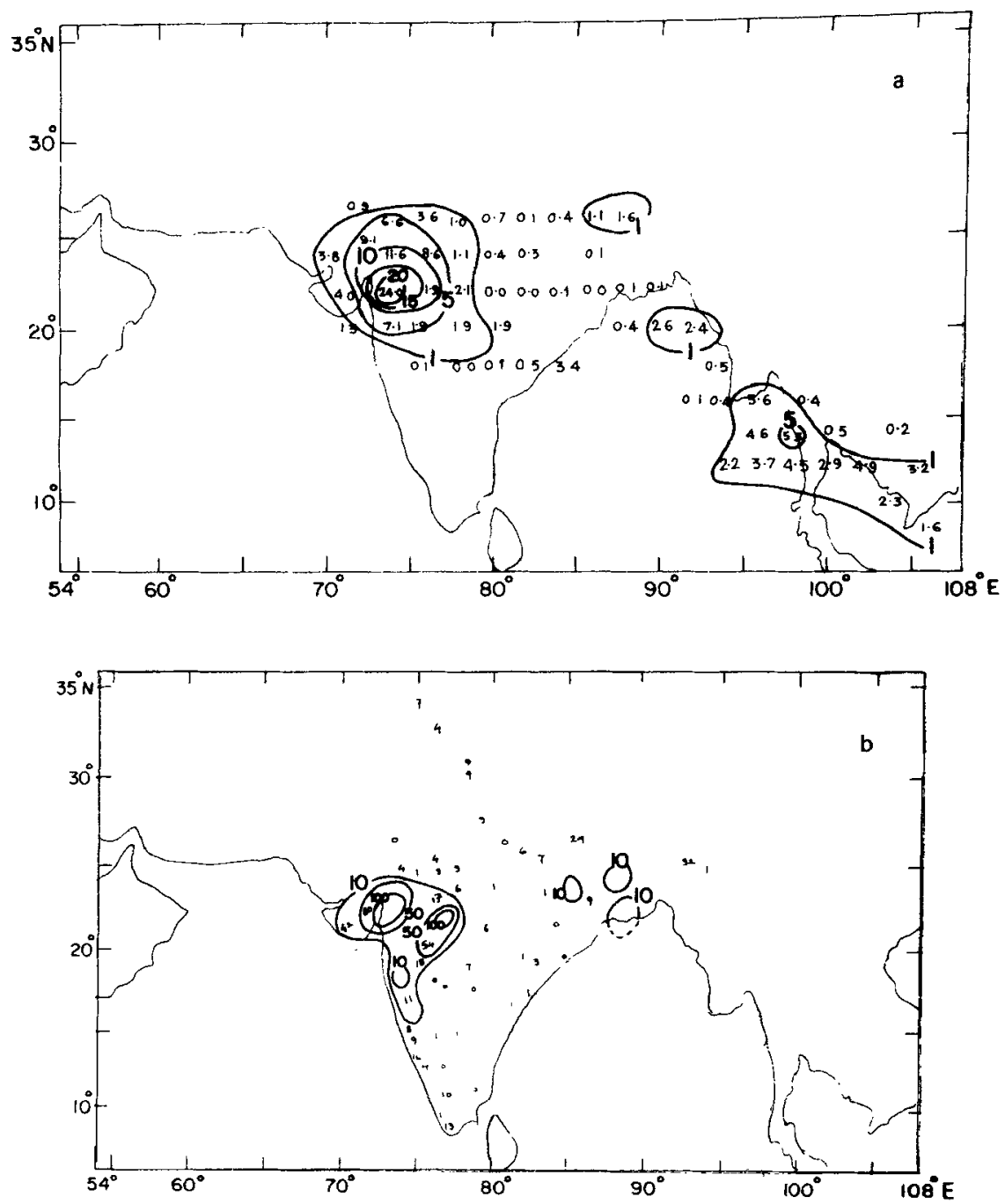

Figure 14. .. Predicted and b. observed, $24 \mathrm{hr}$ total rainfall amounts (mm). 


\section{Conclading remarks}

The model has produced reasonably good forecast upto 24 hours in respect of the circulation patterns, movement of the cyclonic system, cold core in the lower troposphere and warm core above the surface storm and the precipitation region, and beyond that damped significantly. The intensity of wind and vertical velocity are generally found weaker than the actual, particularly over the cyclonic circulation. The rainfall rates are very much underestimated by the model.

Although the model has produced a reasonably good forecast, it is necessary to point out its deficiency. The model suffers severely from the artificial specification of lateral boundary conditions. The tropical quasi-stationary long waves are a major source of energy for short-waves and the rate of energy transfer from longer waves to synoptic and subsynoptic scale waves is found to be quite large even in the time scale of a few days. For a realistic forecast of the synoptic scale of motion, the interaction of shorter waves with longer waves in model atmosphere should be taken into consideration. This could be accomplished by using a high resolution global model with sophisticated scheme of physical processes. Alternately, the boundary data of the regional model could be provided by the solution of a global model in which the regional model is nested. A third alternative could be to extend the domain of regional model in the east-west and north-south directions to ensure the interaction of different scales. In the present experiment, none of the above could be accomplished mainly due to limited computing facility. Another shortcoming of the model which is considered important is the oscillation of the divergence field during integration. After a few sensitivity experiments, it was noted that the present dynamic initialization which was carried out on limited domain is not capable of suppressing the inertial oscillation completely. This is a severe drawback of the model which is again closely linked with the lateral boundaries. As pointed out in $\$ 9.3$ the rainfall rates are underestimated by the model. This could be due to unrealistic moisture analysis particularly in the lower troposphere, lack of proper resolution in the planetary boundary layer, weak vertical velocity and to some extent, underestimation of convective rainfall by the scheme of parametrization of cumulus convection in the region where convective rains are predominant. The weak vertical velocity and slow westward propagation of the cyclonic system are to a large extent due to complete absence of orography from the model. Furthermore, the regional model has coarse resolution in the horizontal and vertical directions and should have one more level in the planetary boundary layer and a horizontal grid size of $100 \mathrm{~km}$. To handle the smooth orography effectively, the model should have the earth's surface with detailed orography as a coordinate surface (Phillips 1957). Some of these problems will be examined in future studies.

\section{Acknowledgements}

The author thanks Dr Bh V Ramana Murty and Shri D R Sikka for their keen interest. Part of the work was done by the author as wmo Fellow at Meteorological Research Institute, Tsukuba, Japan. He thanks Dr M Yamasaki and Mr H Ohnishi for their helpful discussions in programming the model physics. Thanks are due to Shri A Bandyopadhyay for assistance. 


\section{List of symbols}

$C_{p} \quad$ specific heat of air at constant pressure

$F_{\text {a }}$ sub grid scale diffusion of water vapour

$F_{T}$ sub grid scale diffusion of heat

$F_{\text {v }}$ horizontal diffusion of $u$-momentum

$F_{v} \quad$ horizontal diffusion of $v$-momentum

$f$ Coriolis parameter

$f^{*} f-m^{2} u \frac{\partial}{\partial y}\left(\frac{1}{m}\right)$

$f_{0}$ Coriolis parameter at $22^{\circ} \mathrm{N}$

$g$ acceleration due to gravity

$H \quad$ vertical eddy flux of sensible heat

$M$ sum of precipitation and evaporation

$m$ map factor

$p$ pressure

$q \quad$ specific humidity

$R \quad$ gas constant for dry air

$T$ temperature

$T$ convective cloud temperature

$T_{v} \quad$ virtual temperature

$t$ time

$u \quad$ zonal wind speed positive towards east

$u_{o b}$ observed zonal wind speed

$v$ meridional wind speed positive towards north

$v_{o b}$ observed meridional wind speed

$W$ vertical eddy flux of water vapour

$x$ coordinate axis towards east

$y$ coordinate axis towards north

$z$ geopotential height

$\beta \quad$ Rossby parameter $\left(\equiv \frac{\mathrm{d} f}{\mathrm{~d} y}\right)$

$\theta$ potential temperature

$\tau$ eddy stress vector

$\phi$ geopotential

$\psi$ stream function

$\omega \quad$ vertical $p$-velocity

$\omega_{s}$ vertical $p$-velocity at the surface

$\frac{\mathrm{d} Q}{\mathrm{~d} t}$ diabatic heating

\section{References}

Asselin R 1972 Mon. Weather Rev. 100487

Bedi H S, Datta R K and Krichak R L 1976 Meteorol. Gidrol. 539 (in Russian)

Das P K and Bedi H S 1978 Indian J. Meteor. Hydrol. Geophys. 29375

Electronic Computation Centre JMA 1980 Outline of the operational numerical weather prediction at JMA, Tokyo, 21 pp 
Kanamitsu M 1975 On numerical prediction over global tropical belt Report 75-1, Department of Meteorology, Florida State University, 97 pp

Kiangi P M R 1977 Arch. Meteorol. Geophys. Bioklimatol. A26 349

Krishnamurti T N, Kanamitsu M, Godbole R, Chang C B, Carr F and Chow J H 1976 J. Meteorol. Soc. Jpn 54208

Krishnamurti T N, Molinari J, Pan H L and Wong V 1977 Pure Appl. Geophys. 1151357

Kuo H L 1965 J. Atmos. Sci. 2240

Kuo H L 1974 J. Atmos. Sci. 311232

Leith C E 1969 Proc. WMO/IUGG symposium on numerical weather prediction, Tokyo 1968 (Tokyo: Japan Meteorological Agency) Vol. 1, p. 41

Manabe S, Smagorinsky J and Strickler R F 1965 Mon. Weather Rev. 93769

Okamura Y 1975 J. Meteorol. Soc. Jpn 53175

Phillips N A 1957 J. Meteorol. 14184

Singh S S 1977 Some aspects of prognostic and diagnostic studies of Indian summer monsoon. Ph.D. thesis, Banaras Hindu University, Varanasi, India, 32-74

Singh S S 1983 A limited area five level primitive equation model, Scientific Report R-038, Indian Institute of Tropical Meteorology, Pune

Singh S S and Saha K R 1976 Proc. of IITM Symp. on Tropical Monsoons, Pune, India 1976 p. 43

Singh S S, Kulkarni A A and Sikka D R 1980 Mon. Weather Rev. 1081315

Temperton C 1976 Q. J. R. Meteorol. Soc. 102297

Winninghoff F J 1973 Mon. Weather Rev. 10179 